\title{
PENGEMBANGAN MEDIA PEMBELAJARAN MATERI LINGKARAN BERBASIS ADOBE FLASH PADA SISWA KELAS VIII DI MADRASAH TSANAWIYAH
}

\author{
Egi Adha Juniawan ${ }^{1}$, Jajang Miharja ${ }^{2}$ \\ ${ }^{1}$ STKIP La Tansa Mashiro \\ egiadha@latansamashiro.ac.id, jajangmiharja@latansamashiro.ac.id
}

\begin{abstract}
ABSTRAK
Penelitian ini dilatarbelakangi karena perlunya rangsangan terhadap penyampaian informasi kepada peserta didik. Maka dari itu, penelitian ini bertujuan untuk mengembangkan media pembelajaran pada materi lingkaran berbasis adobe flash professional cs 6 agar peserta didik termotivasi dalam proses pembelajaran. Metode penelitian yang digunakan adalah Research and Development (R \& D) dengan model penelitian ADDIE, tetapi penelitian ini hanya sampai pada tahap implementation. Hasil penelitian menunjukan respon kelayakan media pembelajaran pada kelompok kecil diperoleh nilai rata-rata sebesar 3,57 dan respon kelayakan media pembelajaran pada kelompok besar diperoleh nilai rata-rata sebesar 3,60. Hal ini menunjukan pengembangan media pada materi lingkaran berbasis adobe flash professional cs 6 menarik dan layak digunakan dalam pembelajaran.
\end{abstract}

Kata Kunci : Media Pembelajaran, Lingkaran, Adobe Flash Professional CS 6

\begin{abstract}
This research is motivated because of the need for stimulation to convey information to students. Therefore, this study aims to develop learning media on circle material based on Adobe Flash Professional CS 6 so that students are motivated in the learning process. The research method used is Research and Development (R \& D) with the ADDIE research model, but this research only reaches the implementation stage. The results showed that the response to the feasibility of learning media in small groups obtained an average value of 3.57 and the response to the feasibility of learning media in large groups obtained an average value of 3.60. This shows the development of media on circle material based on Adobe Flash Professional CS 6 which is interesting and suitable for use in learning.
\end{abstract}

Keywords: Learning Media, Circle, Adobe Flash Professional CS 6

\section{PENDAHULUAN}

Masyarakat pada abad 21 dituntut untuk lebih kreatif dan inovatif dalam menghadapi berbagai situasi. Pada abad 21 ini, pendidikan harus mampu menjamin peserta didik untuk memiliki berbagai keterampilan yaitu keterampilan belajar dan berinovasi, keterampilan menggunakan teknologi informasi, dan keterampilan untuk hidup (Wijaya, Sudjimat, \& Nyoto, 2016). Melalui Pendidikan seseorang dituntut untuk mengembangkan kemampuan dan keterampilan yang dimilikinya untuk terus berinovasi dan kreatif dalam bidang yang 
diampunya (Juniawan, 2020). Inovasi dalam bidang Pendidikan sangat cepat perkembangannya, salah satunya dalam media pembelajaran. Media pembelajaran digunakan sebagai alat untuk membantu meningkatan minat dan motivasi belajar peserta didik, memberikan dampak yang positif terhadap psikologi peserta didik serta membantu peserta didik dalam memahami konsep sebuah materi (Susanti, 2016). Selain itu, media pembelajaran yang menarik dapat merangsang peserta didik untuk belajar (Rosiyanti, 2020). Penggunaan media pembelajaran menjadi lebih popular karena merangsang cara-cara baru dalam penyampaian informasi kepada peserta didik yang meliputi aksesibilitas, usabilitas dan individualisasi dalam memenuhi kebutuhan setiap peserta didik (Leow \& Neo, 2014). Penelitian yang dilakukan (Muhson, 2010) tentang pengembangan media pembelajaran berbasis teknologi informasi menunjukan bahwa penggunaan media pembelajaran ekonomi dapat memperlancar proses pembelajaran dan mengoptimalkan hasil belajar sehingga pendidik seyogyanya mampu memilih dan mengembangkan media yang tepat agar proses pembelajaran berjalan efektif dan efisien. Fitur-fitur dalam media pembelajaran seperti hiasan grafis, kemampuan mengatur suara, menghidupkan gambar yang bergerak dan video memberikan rangsangan yang lebih luas kepada peserta didik baik secara verbal dan visual sehingga meningkatkan keterlibatan peserta didik dalam pembelajaran (Teoh \& Neo, 2007). Penelitian yang dilakukan oleh (Prawira, 2013) tentang pengimplementasian media pembelajaran berbasis multimedia interaktif pada mata pelajaran matematika di sekolah dasar menunjukan bahwa media pembelajaran interaktif dapat meningkatkan minat belajar siswa dalam mempelajari operasi perkalian dan pembagian pada mata pelajaran matematika di sekolah dasar dikarenakan memberikan pengalaman bermakna melalui tampilan yang menarik dan menyenangkan melalui permainan (game).

Selain itu, salah satu platform yang dapat dimanfaatkan untuk membuat suatu media pembelajaran berbasis multimedia interaktif adalah Adobe Flash. Adobe Flash merupakan gabungan konsep pembelajaran dengan teknologi audiovisual yang mampu menghasilkan fitur-fitur baru yang dapat dimanfaatkan dalam pembelajaran. Fitur - fitur yang ada dalam Adobe Flash mampu mendesain animasi-animasi yang lebih menarik, tidak monoton dan memudahkan penyampaian materi. Selain itu, Adobe flash professional cs 6 memiliki berbagai fitur-fitur yang mendukung dalam pembuatan media pembelajaran interaktif seperti fitur video, audio, dan lain-lain. Penelitian yang telah dilakukan oleh (Hamidi, 2017) tentang Pengembangan Media Pembelajaran Interaktif Pendidikan Agama Islam Berbasis Adobe Flash Professional Cs 6 Untuk Mendukung Implementasi Kurikulum 2013 menunjukan 
bahwa Media Pembelajaran Interaktif Pendidikan Agama Islam Berbasis Adobe Flash Profesional CS 6 untuk Mendukung Implemenasi Kurikulum 2013 layak digunakan sebagai sumber belajar siswa kelas VII SMP. Selain itu, pembelajaran dengan menggunakan adobe flash professional cs 6 akan membantu ketertarikan siswa terhadap materi pembelajaran matematika yang dimana hampir Sebagian siswa Sekolah Menengah Pertama dan Sederajat banyak yang tidak menyukai mata pelajaran matematika. Hal ini sejalan dengan penelitian yang telah dilakukan oleh (widyanto, 2016) tentang pengembangan media pembelajaran berbasis adobe flash professional cs 6 pada materi teorema pythagoras untuk siswa kelas VIII menunjukan bahwa siswa memberikan respon positif dimana nilai rata-rata respon siswa 3,103 dengan presentase yang didapatkan 77,504\% yang menunjukan siswa menyukai pembelajaran dengan media pembelajaran berbasis adobe flash professional cs 6. Salah satu penilaian hasil belajar matematika siswa yang didapat dari guru bidang studi matematika di SMP Pondok Pesantren La Tansa 2 pada tahun pelajaran 2018/2019 dapat di lihat pada tabel berikut ini.

Tabel 1. Persentase Ketercapaian KKM Siswa Kelas VIII-1 SMP Pondok Pesantren La Tansa 2

\begin{tabular}{lcccc}
\hline \multicolumn{1}{c}{ Materi Pokok } & \multirow{2}{*}{ KKM } & \multirow{2}{*}{ Jumlah Siswa } & \multicolumn{2}{c}{ Ketercapaian KKM } \\
\cline { 4 - 5 } & & & Jumlah Siswa & $(\%)$ \\
\hline Bangun Ruang Sisi Datar & 70 & 32 & 21 & 65,6 \\
Teorema Phytagoras & 70 & 32 & 20 & 62,5 \\
Peluang & 70 & 32 & 14 & 43,7 \\
Lingkaran & 70 & 32 & 14 & 43,7 \\
\hline
\end{tabular}

Sumber data : Guru Matematika SMP Pondok Pesantren La Tansa 2

Berdasarkan hasil observasi awal yang dilakukan peneliti pada tanggal 20 Januari 2020 dan 27 Januari 2020 di SMP Pondok Pesantren La Tansa 2 melalui wawancara dengan salah satu guru matematika di sekolah tersebut, materi lingkaran dan peluang merupakan materi yang cukup sulit untuk dipahami oleh siswa dibandingkan dengan materi lainnya. Materi tentang lingkaran, yakni pengukuran sudut pusat, sudut keliling, panjang busur, luas juring dan tembereng dalam lingkaran merupakan salah satu materi pelajaran matematika siswa kelas VIII SMP/Mts.

Ada beberapa masalah yang diindikasikan sebagai penyebab materi tentang lingkaran sebagai salah satu materi yang cukup sulit untuk dipahami siswa antara lain kemampuan pemahaman konsep matematika siswa masih kurang, sebagian siswa hanya mengandalkan hafalan, siswa kurang memahami materi prasyarat dan ada bagian dalam materi tersebut yang baru didapat dan dipelajari di kelas VIII.

Menurut Norsanty dan Chairani (2016) Lingkaran merupakan salah satu materi yang wajib dikuasai oleh peserta didik karena termuat dalam Kompetensi Dasar (KD) mata 
pelajaran Matematika. Salah satu kompetensi dasar yang harus dicapai oleh peserta didik pada materi Lingkaran adalah memahami unsur, keliling, dan luas lingkaran. Penyajian materi dengan cara memberikan rumus dan meminta siswa untuk menghafal serta mengerjakan soal-soal tidak akan mampu membuat siswa mengkonstruksi pengetahuan yang dimilikinya untuk membangun konsep materi tersebut.

\section{METODE PENELITIAN}

Metode penelitian yang digunakan dalam penelitian ini adalah Research and Development (R \& D), karena bertujuan untuk mengembangkan suatu produk berdasarkan kebutuhan yang terdiri dari hasil analisis data penelitian terdahulu (Mentari et al., 2018). Model penelitian yang dipakai adalah model ADDIE merupakan model pengembangan desain instruksional yang dikembangkan oleh Dick and Carey (Ula \& Fadila, 2018). Menurut Ula dan Fadila (2018) model penelitian ADDIE ini terdapat 5 tahapan dimana terdiri dari Analysis, Design, Development, Implementation or Dilevery and Evaluation. Sedangkan dalam penelitian ini, peneliti hanya menggunakan sampai pada tahap implementation. Penelitian ini dilakukan di MTs Pondok Pesantren La Tansa 2 dimana terbagi menjadi dua kelompok yaitu kelompok uji coba kecil yang terdiri dari 10 siswa dan uji coba besar yang terdiri dari 30 siswa di kelas VIII MTs Pondok Pesantren La Tansa 2. Adapun konversi nilai yang digunakan dalam penelitian ini sebagai berikut :

Tabel 2. Konversi Nilai

\begin{tabular}{cccc}
\hline \multirow{2}{*}{ Data Kuantitatif } & \multicolumn{2}{c}{ Skor } & \multirow{2}{*}{ Kriteria } \\
\cline { 2 - 3 } & Rumus & Skor & Sangat Baik \\
\hline 5 & $\mathrm{X}>\overline{X_{l}}+1,8 \mathrm{Sb}_{\mathrm{i}}$ & $\mathrm{X}>4,2$ & Baik \\
3 & $\overline{X_{l}}+0,6 \mathrm{Sb}_{\mathrm{i}}<\mathrm{x} \leq \overline{X_{l}}+1,8 \mathrm{Sb}_{\mathrm{i}}$ & $3,4<\mathrm{x} \leq 4,2$ & Cukup \\
2 & $\overline{X_{l}}-0,6 \mathrm{Sb}_{\mathrm{i}}<\mathrm{x} \leq \overline{X_{l}}+0,6 \mathrm{Sb}_{\mathrm{i}}$ & $2,6<\mathrm{x} \leq 3,4$ & Kurang \\
1 & $\overline{X_{l}}-1,8 \mathrm{Sb}_{\mathrm{i}}<\mathrm{x} \leq \overline{X_{l}}-0,6 \mathrm{Sb}_{\mathrm{i}}$ & $1,8<\mathrm{x} \leq 2,6$ & Sangat Kurang \\
\hline
\end{tabular}

Sumber: Eko Putro Widoyoko (2009:38)

\section{HASIL DAN PEMBAHASAN}

Materi lingkaran yang dibahas dalam penelitian ini berkaitan tentang pengertian dan unsur-unsur lingkaran, luas dan keliling lingkaran, panjang busur dan luas juring lingkaran, dan hubungan antara luas lingkaran, panjang busur lingkaran dan luas juring lingkaran. Pembelajaran yang dilakukan sebelumnya untuk memahami materi lebih kepada metode ceramah, maka adanya media pembelajaran ini bertujuan untuk menarik minat belajar siswa dan layak digunakan dalam pembelajaran untuk membantu siswa dalam memahami materi terutama pada materi lingkaran. Kelebihan dari media pembelajaran berbasis adobe flash cs 6 yang telah dikembangkan yaitu kejelasan materi yang disertai contoh, terdapat video 
penjelasan materi dan ada evaluasi untuk siswa serta memiliki tampilan yang menarik. Adapun untuk tahapan ADDIE dalam pengembangan media pembelajaran yang telah dikembangkan terlihat pada tabel berikut:

Tabel 3. Tahapan ADDIE dalam pengemabangan Media Pembelajaran berbasis Adobe Flash

\begin{tabular}{|c|c|c|}
\hline Tahapan & Kegiatan & Hasil \\
\hline Analysis & $\begin{array}{l}\text { 1. Analisis mata pelajaran } \\
\text { 2. Analisis KI, KD dan Indikator } \\
\text { 3. Analisis karakteristik Siswa } \\
\text { 4. Analisis media pembelajaran } \\
\text { 5. Analisis Lingkungan Belajar }\end{array}$ & DRAF I \\
\hline Design & $\begin{array}{l}\text { 1. Bentuk Penyampaian Pesan } \\
\text { 2. Stratgi Instruksional } \\
\text { 3. Instrumen Penilaian dan Evaluasi } \\
\text { 4. Memetakan Unsur Media } \\
\text { 5. Sistematika media pembelajaran }\end{array}$ & DRAF II \\
\hline Development & $\begin{array}{l}\text { 1. Pengumpulan Bahan } \\
\text { 2. Pembuatan Media } \\
\text { 3. Pengujian (Black Box) } \\
\text { 4. Distribusi } \\
\text { 5. Uji Coba }\end{array}$ & Produk \\
\hline Implementation & $\begin{array}{l}\text { 1. Pengorganisasian Lingkungan Belajar } \\
\text { 2. Uji Coba Guru dan siswa } \\
\text { 3. Uji Coba Lapangan Terbatas }\end{array}$ & Produk Akhir \\
\hline
\end{tabular}

Sebelum membuat media pembelajaran, terlebih dahulu dilakukan analisis kebutuhan terhadap Media pembelajaran yang akan dikembangkan dengan adobe flash professional cs 6 . Analisis kebutuhan yang dilakukan meliputi analisis materi pelajaran, analisis Kompetensi Inti, Kompetensi Dasar dan Indikator, analisis karakteristik siswa dan analisis lingkungan belajar. Dari hasil analisa tersebut, dikumpulkan bahan-bahan yang akan digunakan dalam pembuatan media pembelajaran. Setelah bahan-bahan terkumpul, maka tahap selanjutnya yaitu tahap design. Pada tahap ini kegiatan yang dilakukan adalah memilih penyampaian pesan, membuat strategi intruksional, mendesain kerangka media dan instrument evaluasinya, memetakan unsur media, dan menyusun sistematika media pembelajaran berbasis adobe flash professional cs 6 .

Selanjutnya pada tahap pengembangan dilakukan proses pembuatan media pembelajaran berbasis adobe flash professional cs 6 dengan mengikuti design yang telah dibuat sebelumnya. Pada tahap ini, media pembelajaran yang telah dibuat kemudian akan dievaluasi dan divalidasi oleh para ahli. Hal ini bertujuan untuk mendapatkan masukan terkait media pembelajaran dan mendapatkan layak atau tidaknya media pembelajaran ini digunakan untuk pembelajaran materi lingkaran. Validasi terhadap media pembelajaran yang dilakukan meliputi validasi ahli media, ahli materi dan ahli bahasa. Masukan para ahli terhadap media pembelajaran berbasis adobe flash professional cs 6 ini adalah bagian dari revisi yang harus dilakukan pada media pembelajaran agar lebih menarik baik tampilan ataupun kontennya. Masukan-masukan tersebut seperti menambah sound diawal log in, 
menambah animasi dimenu utama, memasukan video animasi di menu video, pemadatan materi, dan perbaikan bahasa dalam penyampaian materi ataupun evaluasi. Selain itu, angket yang diberikan kepada para ahli untuk mendapatkan layak atau tidaknya media pembelajaran ini digunakan.

Penilaian validasi ahli terhadap media pembelajaran ini menunjukkan nilai yang valid diantaranya ahli materi nilai rata-rata sebesar 3,61 dengan dua aspek yaitu aspek pembelajaran nilai rata-rata sebesar 3,67 dan aspek isi nilai rata-rata sebesar 3,56, ahli media nilai rata-rata sebesar 3.50 dan ahli bahasa nilai rata-rata sebesar 4.13.

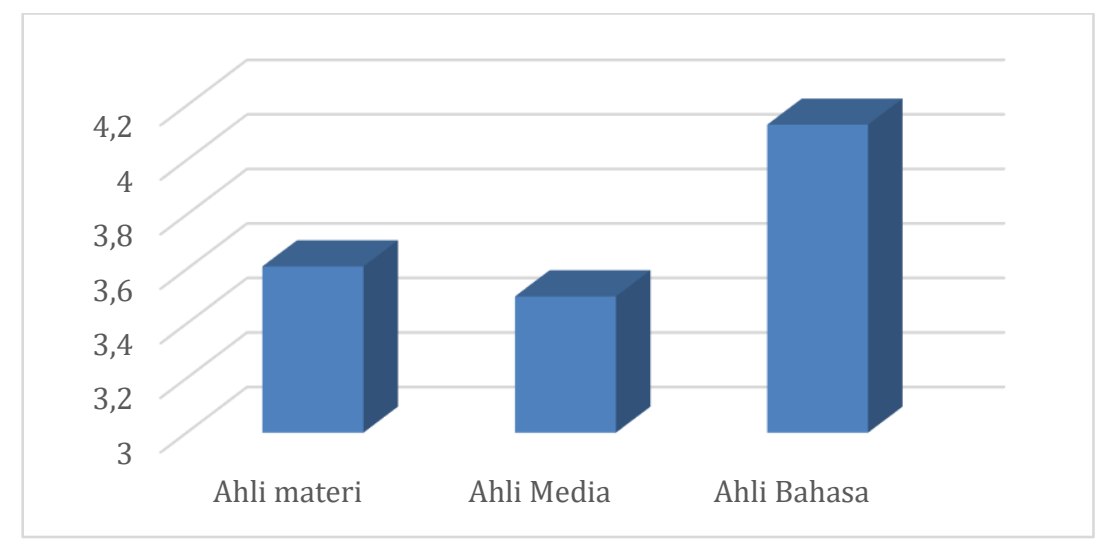

Gambar 1. Persentasi Penilaian para ahli

Media pembelajaran berbasis adobe flash cs 6 yang dikembangkan dan sudah direvisi sesuai ahli media, ahli materi dan ahli bahasa terlihat seperti gambar berikut.

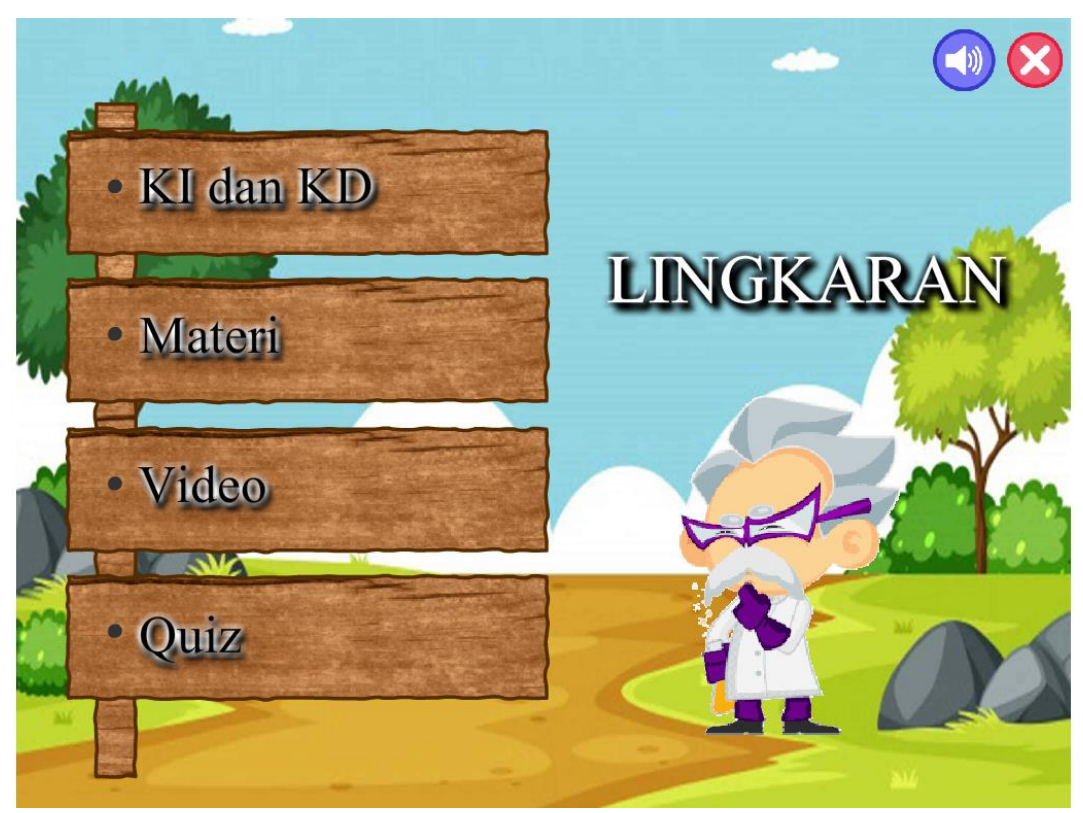

Gambar 2. Menu Utama Media Pembelajaran 
Selanjutnya masuk pada tahap implementation, dimana pada tahap ini media pembelajaran yang telah dinyatakan valid dan layak digunakan kemudian akan diujicobakan pada siswa dan guru. Ujicoba kepada guru dilakukan untuk mendapatkan kemenarikan terhadap media pembelajaran yang dikembangkan. Hasil rata-rata penilaian yang diperoleh oleh guru sebesar 3,7 dengan kategori baik dan layak digunakan. Ujicoba yang dilakukan pada kelompok kecil yang terdiri dari 10 orang siswa diperoleh nilai rata-rata sebesar 3,57 dengan kategori baik dan layak digunakan. Sedangkan ujicoba yang dilakukan pada kelompok besar yang terdiri dari 30 orang siswa diperoleh nilai rata-rata sebesar 3,60 dengan kategori baik dan layak digunakan.

Tabel 4. Skala Uji Coba Kecil

\begin{tabular}{cccc}
\hline Jumlah Skor & Skor Kelayakan & $\begin{array}{c}\text { Skor } \\
\text { Kelayakan Rata-rata }\end{array}$ & Kriteria \\
\hline 535 & $3,4<\mathrm{x} \leq 4,2$ & 3.57 & Baik \\
\hline
\end{tabular}

Tabel 5. Skala Uji Coba Besar

\begin{tabular}{|c|c|c|c|}
\hline Jumlah Skor & Skor Kelayakan & $\begin{array}{c}\text { Skor } \\
\text { Kelayakan Rata-rata } \\
\end{array}$ & Kriteria \\
\hline 1618 & $3,4<x \leq 4,2$ & 3.60 & Baik \\
\hline
\end{tabular}

Pada pernyataan Ketepatan pemilihan warna background dan warna tulisan hampir Sebagian besar ressponden atau siswa pada kelompok besar mengatakan sangat bagus pada pernyataan tersebut. Sedangkan respon dari guru yang dominan mengatakan sangat bagus terdapat pada pernyataan Tampilan animasi yang disajikan apakah menarik. Berdasarkan angket respon siswa baik kelompok kecil maupun kelompok besar, pengembangan media pembelajaran pada materi lingkaran berbasis adobe flash professional cs 6 dengan interprestasi menarik sebagai media pembelajaran dan layak digunakan dalam pembelajaran pada materi lingkaran. Hal ini serupa dengan penelitian sebelumnya yang dilakukan oleh Elhaq (2013) tentang pengembangan media pembelajaran berbasis flash Pada materi lingkaran dengan memperhatikan fungsi Kognitif Rigorous Mathematical Thinking (RMT) menunjukan bahwa hasil media pembelajaran berbasis flash pada materi lingkaran dengan memperhatikan fungsi kognitif Rigorous Mathematical Thinking (RMT) yang berkualitas baik karena telah memenuhi kriteria valid, efektif dan valid.

\section{KESIMPULAN}

Berdasarkan hasil penelitian dapat disimpulkan bahwa pengembangan media pembelajaran pada materi lingkaran berbasis adobe flash professional cs 6 menarik dan layak 
digunakan dalam pembelajaran. Hal ini terlihat dari nilai rata-rata respon kelompok kecil sebesar 3,57 dan nilai rata-rata respon kelompok besar sebesar 3,60.

\section{REFERENSI}

El-haq, M. N. S. A., Budiarto, M. T. 2013. Media Pembelajaran Berbasis Flash Pada Materi Lingkaran Dengan Memperhatikan Fungsi Kognitif Rigorous Mathematical Thinking (RMT). [Online] tersedia : https://jurnalmahasiswa.unesa.ac.id/index.php/mathedunesa/article/download/3888/ 6432. [08 Juni 2021]

Hamidi, N. 2017. Pengembangan Media Pembelajaran Interaktif Pendidikan Agama Islam Berbasis Adobe Flash Professional Cs 6 Untuk Mendukung Implementasi Kurikulum 2013. [Online] tersedia: http://ejournal.uinsuka.ac.id/tarbiyah/index.php/jpai/article/view/1806. [16 Juli 2020]

Juniawan, E.A. 2020. "pengaruh mathematics self-efficacy terhadap prestasi belajar matematika siswa kelas VIII Mts. Daar El Qolam”, Geomath. Vol. 1 (1), pp: 41

Leow, F. T., \& Neo, M. (2014). "Interactive multimedia learning: Innovating classroom education in a Malaysian university". Turkish Online Journal of Educational Technology, 13(2), pp: 99-110.

Mentari, D., Sumpono, S., \& Ruyani, A. 2018. "Pengembangan media pembelajaran ebook berdasarkan hasil riset elektroforesis 2-d untuk mengukur kemampuan berpikir kreatif mahasiswa". PENDIPA Journal of Science Education, Vol 2(2), pp: 131-134

Muhson, A. 2010. "Pengembangan Media Pembelajaran Berbasis Teknologi Informasi”. Jurnal Pendidikan Akuntansi Indonesia, Vol 8 (2), pp: 1-10

Norsanty, U.O., Chairani, Z. 2016. Pengembangan Lembar Kerja Siswa (LKS) Materi Lingkaran Berbasis Pembelajaran Guided Discovery Untuk Siswa SMP Kelas VIII. [Online] tersedia: https://www.neliti.com/id/publications/176907/pengembanganlembar-kerja-siswalks-materilingkaran-berbasis-pembelajaran-guide. [14 Agustus 2020]

Prawira, F. R. (2013). "Pengimplementasian media pembelajaran berbasis multimedia interaktif pada mata pelajaran matematika di sekolah dasar". Scholaria: Jurnal Pendidikan Dan Kebudayaan, 66, pp: 37-39.

Rosiyanti, H., Eminita V., Riski. 2020. desain media pembelajaran geometri ruang berbasis powtoon. [Online] tersedia: https://jurnal.umj.ac.id/index.php/fbc/article/view/6831/4289 [20 Agustus 2020]

Susanti, R.D., Effendi, M.M. 2020. Efektivitas penggunaan edmodo dalam pelaksanaan ulangan harian matematika. [Online] tersedia: https://jurnal.umj.ac.id/index.php/fbc/article/view/4756/4265 [20 Agustus 2020]

Teoh, B., \& Neo, T.-K. 2007. Interactive Multimedia Learning: Students' Attitudes and Learning Impact in an Animation Course. [Online] tersedia: https://files.eric.ed.gov/fulltext/ED499660.pdf [25 Agustus 2020]

Ula, I. R., \& Fadila, A. 2018. "Pengembangan E-Modul Berbasis Learning Content Development System Pokok Bahasan Pola Bilangan SMP”. Desimal: Jurnal Matematika, Vol 1(2), pp: 201.

Widyanto, E. 2016. Pengembangan Media Pembelajaran Berbasis Adobe Flash Professional Cs 6 Pada Materi Teorema Pythagoras Untuk Siswa Kelas VIII. [Online] tersedia: 
https://jurnalmahasiswa.unesa.ac.id/index.php/mathedunesa/article/view/16679. [16 Juli 2020]

Wijaya, E. Y., Sudjimat, D. A., \& Nyoto, A. (2016). "Transformasi Pendidikan Abad 21 Sebagai Tuntutan Pengembangan Sumber Daya Manusia di Era Global". Prosiding Seminar Nasional Pendidikan Matematika, 1, pp: 263-278. 